\title{
ACUTE TICK BITE (ACARI : IXODIDAE)
}

\section{Dr. Harshita Jain}

\section{Dr. Sanath Aithal*}

Junior Resident, Department Of Dermatology, Venerology And Leprosy, Teerthanker Mahaveer Medical College And Research Centre, Moradabad, Uttar Pradesh

MD, Professor And HOD, Department Of Dermatology, Venerology And Leprosy, Teerthanker Mahaveer Medical College And Research Centre, Moradabad, Uttar Pradesh *Corresponding Author

ABSTRACT Ticks are tiny crawling blood sucking ectoparasites of vertebrates known to cause a wide variety of dangerous blood-borne illnesses. Disease causing ticks belong to three major families, the Ixodidae/hard tick, the Argasidae/soft tick and the Nuttalliellidae. Infected ticks spread over a hundred diseases, some of which are fatal if undetected. We here presented a case of a male who suspected tick as a acute painful itchy mole over back of the right ear, inside the left ear and over the left eyelid. This case is presented for its rarity, identification of the tick so that the early detection and removal of the parasite. In India, the fatal tick-borne viral diseases that are Cremian-Congo-Haemorrhagic fever and Kyasanur-Forest-Disease were caused by ticks and there are sporadic records available for the occurrence of relapsing fever, lyme disease, Ganjam virus disease and $Q$ fever.

\section{KEYWORDS : Ticks, Tick Bite}

\section{INTRODUCTION}

Ticks are tiny crawling blood sucking ectoparasites playing role as vectors for transmission of many infectious diseases in man and animals known to cause a wide variety of dangerous blood-borne illnesses. The major factor contributing to the appearance of new zoonotic pathogens in human populations is increased contact between humans and wildlife ${ }^{[1]}$. However, many cases of tick infestation present as a pigmented papule (the tick itself). The Humans become the accidental hosts for obtaining blood meal. Sometimes the attached tick is mistaken for skin lesions such as traumatized, papillomatousnevus, melanoma or mole ${ }^{[2-4]}$. As the Current Scenario of TickBorne Diseases in India the fatal tick-borne viral diseases that are Cremian Congo Haemorrhagic fever and Kyasanur Forest Disease were caused by ticks and there are sporadic records available for the occurrence of relapsing fever, lyme disease, Ganjam virus disease and $Q$ fever ${ }^{[5]}$.

\section{CASE REPORT}

A 17 year boy came to skin outpatient department with complain of acute painful itchy lesions. On history there was sudden onset of painful papules over different sites including, behind the right ear, inside the left ear and over the left eyelid buried in the lash hair on the lid margin since 2 days. There was history of itching over the involved sites with no complains of fever. Patient also gave history of residence at forest area near Ramnagar, Uttarakhand.

On examination, black coloured solitary, tender papules were seen over the right retro auricular region [Figure 1], inside the left ear [Figure 2] and over the left eyelid [Figure 3, 4]. There was no other significant skin lesions anywhere else on the body. On closer examination, the papule was moving, with surrounding crusting and erythema and it was evident that it was an tick adherently holding on to the skin, revealed it was a Ixodidae tick[Figure 5,6]. So the diagnosis of acute tick bite was made. The insect was removed by instilling a drop of surgical spirit, then it was gently gripped with fine forceps close to skin, and removed with gentle traction [Figure 7, 8].

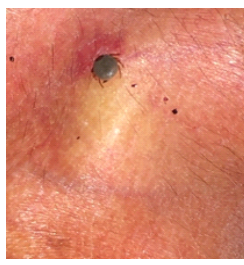

Figure 1: A hyperpigmented mole like appearance of the hard tick attached over

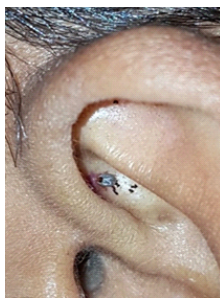

Figure 2: Closer view of the hard tick inside the left ear.

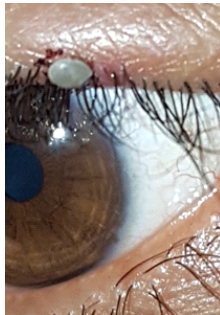

Figure 3: The hard tick attached over the eyelid, buried in the lash hair on the lid margin.

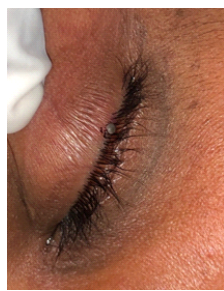

Figure 4: The hard tick attached over the eyelid, buried in the lash hair on the lid margin.

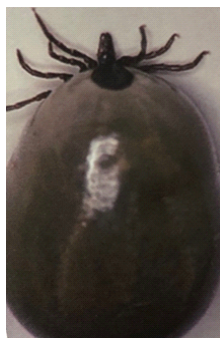

Figure 5 : Picture of a hard tick from Rook's Textbook of Derm 
atology.

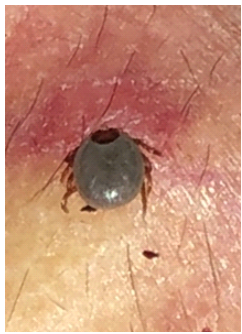

Figure 6 : Picture of a hard tick in our patient.

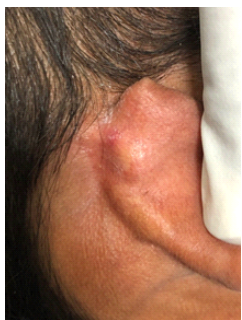

Figure 7 : The papular mark on the skin seen after removal of the hard tick from retro-auricular region.

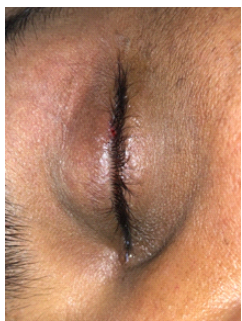

Figure 8: The papular mark on the skin seen after removal of the hard tick from eyelid.

\section{DISCUSSION}

Ticks are associated with human suffering since a long time, as evidenced by earlier records from many countries of the world ${ }^{[6]}$. They are obligate hematophagous ectoparasites ${ }^{[7]}$. Ticks are divided into three major families, the Ixodidae/hard tick, and the Argasidae/soft tick and the Nuttalliellidae (Nuttalliellidae is not much of medical importance) $)^{[8]}$. In the case of ixodid ticks, it is usually the parasite itself that attracts the patient's attention. Larvae, nymphs or adults may be discovered attached to the skin. Acute skin manifestations of Ixodidae includes redness, papules, or thin plaques may form at the site of attachment within 1 to 3 days. The lesion may feel hard and may be surrounded by redness ${ }^{[10]}$. Pruritic papules were a prominent feature of larval Amblyomma tick bites in a case reported by Fisher et al. ${ }^{[1]}$. Acute lesions may sometimes persist and become chronic. Chronic lesions include plaques, papules and nodules ${ }^{[12]}$. The formation of tick bite granuloma are probably responsible of these lesions, which may persist for months or years ${ }^{[13]}$. The other manifestations includes mild swelling or blister formation and can be mild to severely itchy, Necrotic ulcers can form in severe cases ${ }^{[14]}$. It should be removed within 24 to 48 hours of attachment to the host, as its required for infection to occur, early removal can help prevent disease ${ }^{[15]}$. Public health importance of tick borne illness Nuisance, Tick borne relapsing fevers, Tick paralysis, Tick borne Rickettsial fevers, Lyme disease, Tularaemia, Tickborne viral encephalitides and other viral diseases. The main complication of tick bites is secondary infection (Staphyl oco ccus aureus and group A Streptococcus), such as impetigo, ecthyma, erysipelas, cellulitis and superinfected necrotic ulcers ${ }^{[12,13]}$. Finally, tick bites can cause non-dermatological dis e ase such as anaphylaxis, paralysis and other systemic symptoms. Tick paralysis is an ascending flaccid paralysis probably caused by a neurotoxin injected by the feeding tick
${ }^{[16]}$. Occasionally, bulbar paralysis, respiratory failure and death occur.

The methods suggested for tick removal are, application of chloroform, spirit, petrol, iodine, ether, clear nail varnish, lidocaine and kerosene. It should be gently gripped with fine forceps as close to the skin as possible followed by gentle traction $^{[6]}$. Among Surgical methods for tick removal with curved forceps the most preferred method ${ }^{[17]}$. Recently, Cryotherapy has also been reported to be effective in the $\operatorname{process}^{[18]}$.

In our patient, the insect was removed by instilling a drop of surgical spirit, then removed with forceps under aseptic precautions, except for the eyelid where tincture iodine was used. The course of topical and oral antibiotics has been given. Follow up after two week has been done with no fever and other complications. Patient was informed about the signs and symptoms of tick bite related diseases. Tick bite can be prevented by avoidance of tick infested areas and use of tick repellents. This case is presented for its rarity, identification of the tick so that the early detection and removal of the tick and the required follow up for tick born-illness.

\section{REFERENCES}

1. Daszak P, Cunningham AA, Hyatt AD. Anthropogenic environmental change and the emergence of infectious diseases in wildlife. Acta Trop 2001;78:103 16.

2. Novick NL, Reitano M (1986) Tick infestation simulating a traumatized papillomatous nevus. Am J Med 81 (4): 721-722.

3. Halpern SM, Munro DD (1994) Tickborne melanoma?. BMJ 309(6970): 1693.

4. Kallini JR, Khachemoune A (2017) Ticks and tick bites presenting as "Funny Moles": A review of different presentations and a focus on tick-borne diseases. I Clin Aesthet Dermatol 10(3): 46-50.

5. Balakrishnan, Dr. (2017). Current Scenario of Tick-Borne Diseases in India - A Review. Journal Of Communicable Diseases. 49. 6-13. 10.24321/001 9.51 38.2 01707.

6. Burns DA. Diseases caused by arthropods and other noxious animals. In: Burns T, Breathnach S, Cox N, Griffiths C, editors. Rook's Textbook of Dermatology. 8 th ed. Oxford: Blackwell Publishing Ltd; 2010. p. 38.33-6.

7. Domingos A, Antunes S, Borges L, Rosário VE.Rev Soc Bras Med Trop. 2013 May-Jun;46(3):265-9.

8. Vidal Haddad Jr., Michel Raineri Haddad, Mônica Santosand João Luiz Costa Cardoso. Skin manifestations of tick bites in humans. An Bras Dermatol. 2018 Mar-Apr; 93(2): 251-255.

9. Walker, Alan \& Bouattour, Ali \& Camicas, J.L. \& Estrada-Pena, A. \& Horak, Ivan \& Latif, Abdalla \& Pegram, R.G. \& Preston, P.M.. (2003). Ticks of Domestic Animals in Africa: a guide to identification of species.

10. Tick bite : Author: Marie Hartley, Staff Writer, 2009. Updated by Vanessa Ngan Staff writer, 1 February 2014

11. Seidel C, Reinhardt K. Bugging forecast: unknown, disliked, occasion- ally intimate. Bed bugs in Germany meet unprepared people. PLOS One 2013;8:e51083.

12. Barzilai A, Shpiro D, Goldberg I, et al. Insect bite-like reaction in patients with hematologic malignant neoplasms. Arch Dermatol 1999;135:1503-7.

13. Bernardeschi C, Le Cleach L, Delaunay $\mathrm{P}$ et al. Bed bug infestation. BM 2013;346: 1138

14. Marie Hartley, Vanessa Ngan, 2014.Tick bite Dermnetnz.2009.

15. ROBERT L. BRATTON, M.D., Mayo Clinic, Scottsdale, Arizona G. RALPH COREY, M.D., Duke University Medical Center, Durham. 2005 Jun 15;71(12):2323-2330.

16. Rodhain F, Perez C. Précis d'entomologie Médicale et Vétérinaire. Paris: Maloine, 1985

17. McGrath M, Buchan-Hepburn G. Tick bite-A case study. Aust Fam Physician 2012;41:125-6. [PUBMED].

18. Pavlovic M, Alakeel A, Frances C. Tick removal with liquid nitrogen. JAMA Dermatol 2013;149:633. 